\title{
Acute Effect of Ethanol on Intestinal Calcium Transport
}

\author{
Nateetip KRISHNAMRA and Pornpimol BOONPIMOL \\ Department of Physiology, Faculty of \\ Science, Mahidol University, \\ Rama VI Rd., Bangkok 10400, \\ Thailand
}

(Received October 7, 1985)

\begin{abstract}
Summary In vivo studies in rats demonstrated that acute intragastric administration of ethanol $(3 \mathrm{~g} / \mathrm{kg} \mathrm{BW})$ resulted in a reduced net absorption of fluid and calcium. Thirty minutes after an i.v. injection of $2 \mu \mathrm{Ci}$ ${ }^{45} \mathrm{Ca}$, the gastrointestinal ${ }^{45} \mathrm{Ca}$ content in ethanol-treated rats was significantly higher than in controls indicating an increase in calcium secretion. The effect of ethanol on calcium movement was quantitated by measuring calcium fluxes across the in situ duodenal and ileal loops. Ethanol administration suppressed net duodenal calcium absorption by inhibiting the lumen to plasma flux of calcium. In contrast, ethanol enhanced plasma to lumen calcium flux in the ileum, resulting in net calcium secretion.
\end{abstract}

Key Words ethanol, calcium transport, intestinal calcium secretion, intestinal calcium absorption and in situ intestinal loop method

Both chronic(l) and acute ethanol administration(2) have been shown to inhibit net absorption of calcium by everted duodenal gut sacs. Since calcium can also be actively absorbed (3-6) and secreted in the ileum $(4,6-8)$ and the effect of ethanol on ileal calcium transport in rats has not been studied, the present experiments thus aimed to investigate the acute effects of intragastric administration of ethanol on net fluid and calcium absorption in vivo and by using an in situ intestinal loop technique to quantitate the calcium fluxes in the duodenum and ileum.

\section{MATERIALS AND METHODS}

Male Fisher rats weighing $180-200 \mathrm{~g}$ and fed commercial laboratory chow (Gold Coin Ltd., Singapore) served as experimental animals. The animals were fasted for $20 \mathrm{~h}$ with access to tap water before study. In every experiment, $3 \mathrm{ml}$ of $10 \mathrm{mg} \mathrm{CaCl} 2$ dissolved in normal saline or $10 \mathrm{mg} \mathrm{CaCl}$ dissolved in $3 \mathrm{~g} / \mathrm{kg} \mathrm{BW}$ ethanol (given as $20 \% \mathrm{v} / \mathrm{v}$ solution) were given intragastrically to the control and 
ethanol-treated groups, respectively.

In vivo studies. The rats were divided randomly into control and ethanoltreated groups. After being lightly anesthetized with ether the rats received an intragastric administration of normal saline or ethanol. Sixty minutes later, the rats were anesthetized again and through an abdominal incision ligations were made at the cardiac and pyloric sphincters and ileocecal valve. The stomach and small intestine were removed and their contents were determined for volume and calcium.

To study the effect of ethanol on calcium secretion, the rats were anesthetized with sodium pentobarbital $\left(50 \mathrm{mg} / \mathrm{kg} \mathrm{BW}\right.$, i.p.). After tracheostomy, $2 \mu \mathrm{Ci}{ }^{45} \mathrm{Ca}$ (Radiocentre Amersham, $\mathrm{UK}$ ) in $10 \mathrm{mg} / 100 \mathrm{ml} \mathrm{CaCl}_{2}$ solution was injected at $0 \mathrm{~min}$ via the femoral vein cannula. Then an intragastric administration of normal saline or ethanol was given. At 60 min the gastrointestinal tract was exposed and ligations were made as described earlier to isolate the stomach and small intestine. The luminal volume and ${ }^{45} \mathrm{Ca}$ concentration were determined.

In situ intestinal loop studies. Sixty minutes after receiving an intragastric administration of normal saline or ethanol, the rats were anesthetized with sodium pentobarbital and tracheostomized. Through a midline abdominal incision, the distal end of the bile duct, pyloric sphincter and ileocecal valve were ligated. The duodenal loop was prepared by making a ligation $5 \mathrm{~cm}$ distal to the pyloric ligation. The ileal loop was prepared by making a ligation $5 \mathrm{~cm}$ above the ileocecal valve. After the loops were washed with $0.9 \% \mathrm{NaCl}$, they were filled with $1 \mathrm{ml}$ of test solution containing in $\mathrm{mM}, \mathrm{NaCl} 125, \mathrm{NaHCO}_{3} 25, \mathrm{KCl} 4.7, \mathrm{CaCl}_{2} 0.9$ and $\mathrm{MgSO}_{4}$ 1.2 , and approximately $2 \mu \mathrm{Ci} / \mathrm{ml}^{45} \mathrm{CaCl}_{2}$ (pH 7.2). The abdominal opening was closed with wound clips and the body temperature was maintained at $37^{\circ} \mathrm{C}$ with a heating lamp.

After 30 min incubation, the intestinal loops were quickly removed and their content was determined for volume, ${ }^{40} \mathrm{Ca}$ and ${ }^{45} \mathrm{Ca}$ concentration. The loops were then cut lengthwise and blotted on absorbent paper. The mucosa was scraped, weighed and dissolved by heating in $0.1 \mathrm{ml}$ of $0.5 \mathrm{~N} \mathrm{NaOH}$ and brought to a final volume of $1.5 \mathrm{ml}$ with distilled water. The solution was analyzed for ${ }^{45} \mathrm{Ca}$ in a liquid scintillation spectrometer (LKB 1219 Rackbeta) and for ${ }^{40} \mathrm{Ca}$ by atomic absorption spectrophotometry (Varian 575).

The calcium fluxes were calculated according to the following equations modified from Wasserman et al. (9).

$$
\begin{aligned}
\text { Net absorption } & =\frac{\left(V_{\mathrm{i}}\right)\left({ }^{40} \mathrm{Ca}_{\mathrm{i}}\right)-\left(V_{\mathrm{f}}\right)\left({ }^{40} \mathrm{Ca}_{\mathrm{f}}\right)}{L} \\
\mathrm{Ca}_{\mathrm{L}-\mathrm{P}} & =\frac{\left(V_{\mathrm{i}}\right)\left({ }^{45} \mathrm{Ca}_{\mathrm{i}}\right)-\left(V_{\mathrm{f}}\right)\left({ }^{45} \mathrm{Ca}_{\mathrm{f}}\right)}{\left[\left({ }^{45} \mathrm{Ca}_{\mathrm{i}}{ }^{40} \mathrm{Ca}_{\mathrm{i}}+{ }^{45} \mathrm{Ca}_{\mathrm{f}} /{ }^{40} \mathrm{Ca}_{\mathrm{f}}\right) / 2\right] L} \\
\mathrm{Ca}_{\mathrm{P}-\mathrm{L}} & =\mathrm{Ca}_{\mathrm{L}-\mathrm{P}}-\text { net absorption }
\end{aligned}
$$

where $V_{\mathrm{i}}$ is the initial volume of test solution $(\mathrm{ml}) ; V_{\mathrm{f}}$, the final volume of test solu- 
tion $(\mathrm{ml}) ;{ }^{40} \mathrm{Ca}_{\mathrm{i}}$, the initial ${ }^{40} \mathrm{Ca}$ concentration $(\mu \mathrm{g} / \mathrm{ml}) ;{ }^{40} \mathrm{Ca}_{\mathrm{f}}$, the final ${ }^{40} \mathrm{Ca}$ concentration $(\mu \mathrm{g} / \mathrm{ml}) ;{ }^{45} \mathrm{Ca}_{\mathrm{i}}$, the initial ${ }^{45} \mathrm{Ca}$ concentration $(\mathrm{cpm} / \mathrm{ml}) ;{ }^{45} \mathrm{Ca}_{\mathrm{f}}$, the final ${ }^{45} \mathrm{Ca}$ concentration $(\mathrm{cpm} / \mathrm{ml}) ; L$, the length of intestinal loop $(\mathrm{cm}) ; \mathrm{Ca}_{\mathrm{L}-\mathrm{p}}$, lumen to plasma calcium flux; and $\mathrm{Ca}_{\mathrm{P}-\mathrm{L}}$, plasma to lumen calcium flux. It is assumed that the re-entry of ${ }^{45} \mathrm{Ca}$ into the luminal solution is negligible $(3,9)$.

Statistical analyses. Data were presented as means \pm SE. Significance of difference was determined with paired or unpaired Student's $t$-tests.

\section{RESULTS}

\section{In vivo studies}

As shown in Fig. 1, the volumes of test solution remaining in the stomach, small intestine and the total volume in percentage of administered dose were significantly higher in the ethanol-treated group $(p<0.005)$ than in controls. The amounts of calcium (percentage of administered dose) remaining in the stomach, intestine and the total calcium content in the ethanol-treated group (Fig. 2) were also significantly higher than in the control group.

To substantiate the finding that ethanol may decrease intestinal absorption of calcium or increase calcium secretion, ${ }^{45} \mathrm{Ca}$ was injected intravenously and the luminal ${ }^{45} \mathrm{Ca}$ content was determined. As illustrated in Fig. 3, the secretion of ${ }^{45} \mathrm{Ca}$ into the gastrointestinal tract was markedly enhance by ethanol administration.

\section{In situ studies}

Figure 4 shows the effect of ethanol administration on calcium fluxes across the

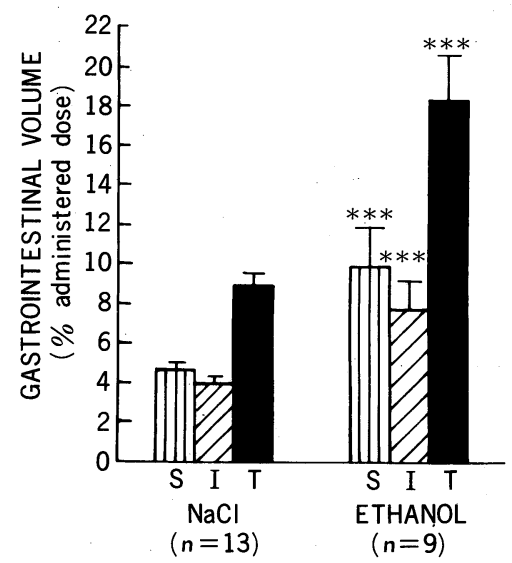

Fig. 1. The fluid volume (percentage of administered dose) in the stomach (S) and small intestine (I), and the total volume (T) in rats $60 \mathrm{~min}$ after intragastric administration of $3 \mathrm{ml}$ of $10 \mathrm{mg} / 100 \mathrm{ml} \mathrm{CaCl} 2$ in $0.9 \% \mathrm{NaCl}$ solution or in $20 \%$ ethanol. Statistical comparisons (unpaired $t$-test) were made between values in the two groups. ${ }^{* * *}$ Denotes $p<0.0005$. 


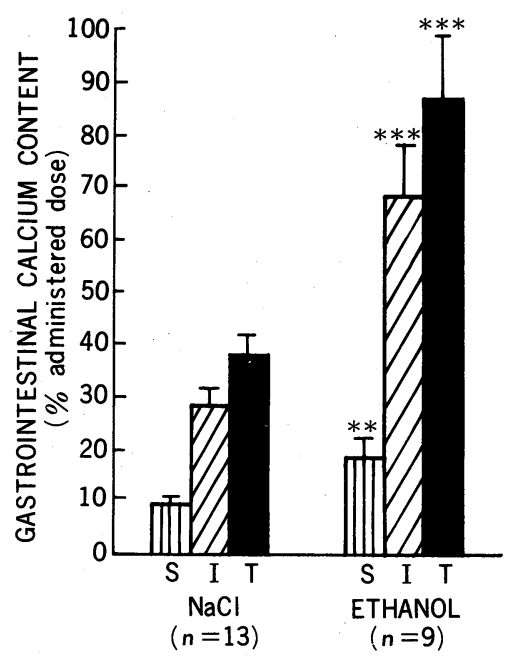

Fig. 2. The luminal calcium content (percentage of administered dose) in the stomach (S) and small intestine (I), and the total calcium content (T), in rats $60 \mathrm{~min}$ after intragastric administration of $3 \mathrm{ml}$ of $10 \mathrm{mg} / 100 \mathrm{ml} \mathrm{CaCl}$ in $0.9 \% \mathrm{NaCl}$ solution or in $20 \%$ ethanol. Statistical comparisons (unpaired $t$-test) were made between values in the two groups. ${ }^{* *}$ Denotes $p<0.005 ;{ }^{* *} p<0.0005$.

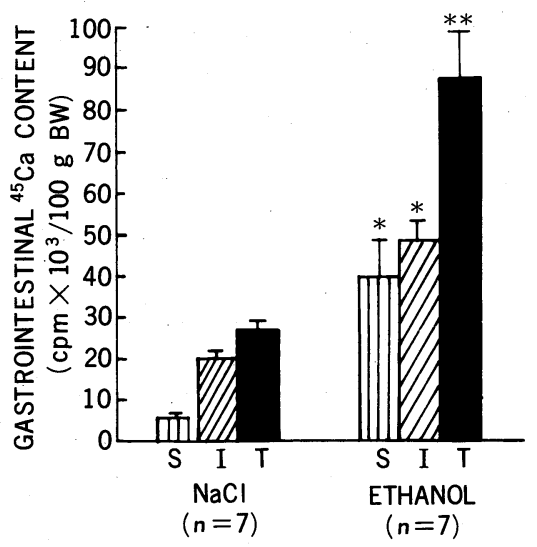

Fig. 3. The gastrointestinal ${ }^{45} \mathrm{Ca}$ content $\left(\mathrm{cpm} \times 10^{3}\right.$ per $\left.100 \mathrm{~g} \mathrm{BW}\right)$ in the stomach (S) and small intestine (I), and the total content $(\mathrm{T})$ in rats $60 \mathrm{~min}$ after intragastric administration of $3 \mathrm{ml}$ of $10 \mathrm{mg} / 100 \mathrm{ml} \mathrm{CaCl} \mathrm{C}_{2}$ in $0.9 \% \mathrm{NaCl}$ solution or in $20 \%$ ethanol and an intravenous injection of $2 \mu \mathrm{Ci}{ }^{45} \mathrm{Ca}$. Statistical comparisons (unpaired $t$-test) were made between the values in the two groups. ${ }^{*}$ Denotes $p<0.05$, ${ }^{* *}$ denotes $p<0.005$.

duodenal and ileal loops. In the duodenum of control rats, $\mathrm{Ca}_{\mathrm{L}-\mathrm{P}}(3.1 \pm$ $0.3 \mu \mathrm{g} / \mathrm{cm} / 30 \mathrm{~min})$ was greater than the $\mathrm{Ca}_{\mathrm{P}-\mathrm{L}}(1.5 \pm 0.2 \mu \mathrm{g} / \mathrm{cm} / 30 \mathrm{~min})$ resulting in a net absorption of $1.7 \pm 0.1 \mu \mathrm{g} / \mathrm{cm} / 30 \mathrm{~min})$. Similarly, in the ileum of control 


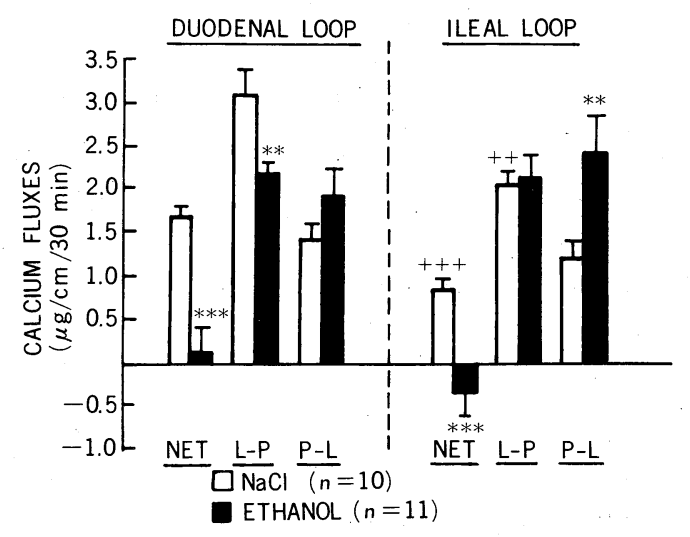

Fig. 4. The effect of an intragastric administration of $3 \mathrm{~g} / \mathrm{kg} \mathrm{BW}$ ethanol on calcium fluxes $(\mu \mathrm{g} / \mathrm{cm} / 30 \mathrm{~min})$ : net absorption, lumen to plasma flux $(\mathrm{L}-\mathrm{P})$ and plasma to lumen flux (P-L) in the duodenal and ileal in situ loops during 30-min incubation. The loops were filled with test solution containing (in $\mathrm{mM}$ ) $\mathrm{NaCl} 125, \mathrm{NaHCO}_{3} 25$, $\mathrm{KCl} 4.7, \mathrm{CaCl}_{2} 0.9$, and $\mathrm{MgSO}_{4} 1.2$, and approximately $2 \mu \mathrm{Ci} / \mathrm{ml}{ }^{45} \mathrm{CaCl}_{2}, \mathrm{pH} 7.2$. Statistical comparisons were made between the duodenum and ileum (paired $t$-test) of the saline control group and between the control and ethanol-treated group (unpaired $t$-test). ${ }^{\dagger \dagger} p<0.005,{ }^{\dagger \dagger} p<0.0005$ (paired $t$-test), ${ }^{* *} p<0.005,{ }^{* * *} p<0.0005$ (unpaired $t$-test).

rats, the $\mathrm{Ca}_{\mathbf{L}-\mathbf{P}}(2.0 \pm 0.2 \mu \mathrm{g} / \mathrm{cm} / 30 \mathrm{~min})$ was greater than the flux in the opposite direction $(1.2 \pm 0.2 \mu \mathrm{g} / \mathrm{cm} / 30 \mathrm{~min})$ resulting in a net calcium absorption of $0.9 \pm 0.1 \mu \mathrm{g} / \mathrm{cm} / 30 \mathrm{~min}$, which was significantly lower $(p<0.0005)$ than that of the net duodenal calcium absorption.

Acute ethanol administration markedly inhibited the net absorption of calcium in the duodenum $(0.1 \pm 0.3 \mu \mathrm{g} / \mathrm{cm} / 30 \mathrm{~min})$ by suppressing the $\mathrm{Ca}_{\mathrm{L}-\mathrm{P}}$ to $2.2 \pm 0.1 \mu \mathrm{g} / \mathrm{cm} / 30 \mathrm{~min}(p<0.005)$ without altering the $\mathrm{Ca}_{\mathrm{P}-\mathrm{L}}$. In the ileum, after ethanol administration there was no change in the $\mathrm{Ca}_{\mathbf{L}-\mathrm{P}}$ but the $\mathrm{Ca}_{\mathbf{P}-\mathrm{L}}$ was markedly increased from the control value to $2.4 \pm 0.5 \mathrm{~g} / \mathrm{cm} / 30 \mathrm{~min}(p<0.005)$ resulting in a reverse of the net absorption in control rats to a net secretion of $0.4 \pm 0.3 \mathrm{~g} / \mathrm{cm} / 30 \mathrm{~min}$ in ethanol-treated rats.

In the in situ experiments the loss of ${ }^{45} \mathrm{Ca}$ from the lumen of the intestinal loop was used to represent $\mathrm{Ca}_{\mathrm{L}-\mathrm{P} .}$. However, it was possible that the ${ }^{45} \mathrm{Ca}$ had accumulated in the mucosa cells so that the reduction in total ${ }^{45} \mathrm{Ca}$ content in the lumen may not strictly represent the $\mathrm{Ca}_{\mathrm{L}-\mathrm{p}}$. Moreover, the mucosal accumulation of ${ }^{45} \mathrm{Ca}$ may provide some information concerning the effect of ethanol on calcium fluxes. Therefore the mucosal accumulation of ${ }^{45} \mathrm{Ca}$ and mucosal calcium content were determined and are shown in Table 1. Consistent with previous reports $(3,16)$ the mucosal calcium content in the ileum was significantly higher than that in the duodenum. The mucosal ${ }^{45} \mathrm{Ca}$ accumulation, on the other hand, was similar. Ethanol administration did not affect these values. This indicates that the reduction 
Table 1. The mucosal calcium content $\left(\mu \mathrm{g} / \mathrm{g}\right.$ wet weight) and mucosal ${ }^{45} \mathrm{Ca}$ accumulation ( $\mathrm{cpm} \times 10^{3} / \mathrm{g}$ wet weight) in the duodenal and ileal in situ loops during the 30 -min incubation period in rats given intragastric administration of $3 \mathrm{ml}$ of $0.9 \% \mathrm{NaCl}$ or $3 \mathrm{~g} / \mathrm{kg}$ BW ethanol.

Statistical comparisons were made between the control and ethanol-treated groups (unpaired $t$-test) and between the duodenum and ileum of the control group (paired $t$ test). * Denotes $p<0.05$ (paired $t$-test). The values of the ethanol-treated group were not significantly different from corresponding control values.

\begin{tabular}{ccc}
\hline & Control & Ethanol \\
\hline Duodenal loop $(n=9)$ & & \\
Mucosal ${ }^{40} \mathrm{Ca}(\mu \mathrm{g} / \mathrm{g}$ wet wt $)$ & $79.3 \pm 11.0$ & $65.7 \pm 7.2$ \\
Mucosal ${ }^{45} \mathrm{Ca}\left(\mathrm{cpm} \times 10^{3} / \mathrm{g}\right.$ wet wt $)$ & $54.1 \pm 11.7$ & $44.0 \pm 7.4$ \\
Ileal loop $(n=9)$ & & \\
Mucosal ${ }^{40} \mathrm{Ca}(\mu \mathrm{g} / \mathrm{g}$ wet wt) & $117.2 \pm 15.1^{*}$ & $104.6 \pm 11.1$ \\
Mucosal ${ }^{45} \mathrm{Ca}\left(\mathrm{cpm} \times 10^{3} / \mathrm{g}\right.$ wet wt $)$ & $64.2 \pm 8.9$ & $60.9 \pm 9.7$ \\
\hline
\end{tabular}

* Denotes $p<0.05$ when compared with duodenal loop.

in the $\mathrm{Ca}_{\mathbf{L}-\mathrm{P}}$ in the duodenum and the increase in the $\mathrm{Ca}_{\mathbf{P}-\mathrm{L}}$ induced by ethanol administration did not involve accumulation of calcium in the mucosa cells but represented changes in calcium movement across the mucosa cells.

\section{DISCUSSION}

Preliminary in vivo experiments demonstrated a reduction of net absorption of fluid and calcium after acute ethanol administration, consistent with previous reports (2). The reduction in net absorption of fluid is partly due to ethanol-induced delay in gastric emptying $(10,11)$ and the direct inhibitory effect of ethanol on fluid absorption (12). The increase in gastric calcium content can be explained in terms of gastric retention of test solution and also by an increase in gastric secretion of calcium as demonstrated by an increase in gastric ${ }^{45} \mathrm{Ca}$ content after an intravenous ${ }^{45} \mathrm{Ca}$ injection. Since acute intragastric administration of ethanol was reported to result in hemorrhagic erosion of the stomach and small intestine $(13,14)$, the observed increase in gastric calcium secretion may have occurred secondarily to gastric mucosa damage.

In the rat, absorption of calcium is more rapid at the duodenum than at the ileum both in vitro $(15,16)$ and in vivo $(3,17,18)$ and is composed of saturable and unsaturable components. Since the concentration of calcium in the luminal solution in the present study was $0.9 \mathrm{~mm}$, which is lower than the plasma ionized calcium concentration $(1.25 \mathrm{~mm})$, calcium absorption across the gut wall was mainly by active transport. Krawitt(2) has suggested that acute ethanol administration inhibited the net duodenal calcium absorption by virtue of its direct toxic effect on 
the duodenal epithelium. Morphological changes $(14,19)$ including ultrastructural alterations (20) of the mucosa of the small intestine after acute and chronic intake of ethanol have been reported but the actual mechanism by which ethanol inhibited calcium absorption has not been elucidated. The present work demonstrated that the inhibition of net duodenal calcium absorption was due to a reduction in the $C a_{\mathbf{L}-\mathbf{P}}$ with $\mathrm{Ca}_{\mathbf{P}-\mathbf{L}}$ being unaltered, suggesting that the damage may reside in the active absorption of calcium. Although the Ca-ATPase activity was not determined, it is possible that ethanol may inhibit the duodenal Ca-ATPase in similar manner to the ethanol-induced inhibition of jejunal Na-K-ATPase (21).

In contrast to the duodenum, the suppressive effect of ethanol on ileal net calcium absorption was due to an increase in the $\mathrm{Ca}_{\mathrm{P}-\mathrm{L}}$ confirming the increase in intestinal ${ }^{45} \mathrm{Ca}$ content seen in the in vivo experiments. Controversies exist concerning the mechanism of calcium absorption in the ileum. It has been reported that the ileum is unresponsive to $1,25(\mathrm{OH})_{2} \mathrm{D}_{3}(22-25)$ and is likely to act only in the nonsaturable transport of calcium. On the other hand, evidence for the existence of active calcium absorption has also been reported $(4,5,26)$. In the present study net absorption of calcium was observed in the ileum at a luminal calcium concentration $(0.9 \mathrm{~mm})$ lower than the plasma ionized calcium concentration although at a rate lower than that occurring in the duodenum. The $\mathrm{Ca}_{\mathrm{L}-\mathrm{P}}$ was lower in the ileum than in the duodenum but the $\mathrm{Ca}_{\mathrm{P}-\mathrm{L}}$ in these two segments were similar. However, ethanol administration markedly enhanced the $\mathrm{Ca}_{\mathrm{P}-\mathrm{L}}$ but did not affect the $\mathrm{Ca}_{\mathrm{L}-\mathrm{P}}$, thus resulting in net secretion of calcium. The different responses seen in the duodenum and ileum may be due to different properties of the transport mechanisms and the different concentrations of ethanol to which they were exposed.

It is agreed that the rat ileum is an important site for calcium secretion (5-8). Evidence has indicated that the $\mathrm{Ca}_{\mathrm{P}-\mathrm{L}}$ in the ileum is mainly paracellular $(6,26)$, increases with increasing medium calcium and does not exhibit saturation kinetics. Moreover, it is not abolished by metabolic inhibitors and is not temperature sensitive(26). Little information is available regarding factors that regulate the calcium secretion. Nevertheless the ultrastructural changes that have been observed in the gastrointestinal tract of rats and humans after the ingestion of ethanol $(14,20)$ may contribute to the observed alterations of intestinal calcium transport.

\section{REFERENCES}

1) Krawitt, E. L. (1975): Effect of ethanol ingestion on duodenal calcium transport. $J$. Lab. Clin. Med., 85 (4), 665-671.

2) Krawitt, E. L. (1974): Effect of acute ethanol administration on duodenum calcium transport. Proc. Soc. Exp. Biol. Med., 146, 406-408.

3) Krawitt, E. L., and Schedl, H. P. (1968): In vivo calcium transport by rat small intestine. Am. J. Physiol. 214 (2), 232-236.

4) Urban, E., and Schedl, H. P. (1969): Comparison of in vivo and in vitro effects of vitamin D on calcium transport in the rat. Am. J. Physiol., 217 (1), 126-130.

5) Walling, M. W., and Kimberg, D. V. (1974): Calcium absorption or secretion by rat

Vol. 32, No. 2, 1986 
ileum in vitro: effects of dietary calcium intake. Am. J. Physiol., 226, 1124-1130.

6) Nellans, H. N., and Kimberg, D. V. (1979): Anomalous calcium secretion in rat ileum: role of paracellular pathway. Am. J. Physiol., 236 (4), E473-E481.

7) Walling, M. W., and Kimberg, D. V. (1973): Active secretion of calcium by adult rat ileum and jejunum in vitro. Am. J. Physiol., 225, 415-422.

8) Munck, B. G., and Rasmussen, S. N. (1977): Paracellular permeability of extracellular space markers across rat jejunum in vitro. Indication of a transepithelial fluid circuit. J. Physiol. (London), 271, 473-488.

9) Wasserman, R. H., Kallfelz, F. A., and Comar, C. L. (1961): Active transport of calcium by rat duodenum in vivo. Science, 133, 883-884.

10) Hunt, J. N., and Pathak, J. D. (1960): The osmotic effects of some simple molecules and ions on gastric emptying. J. Physiol. (London), 154, 254-259.

11) Barboriak, J. J., and Meads, R. C. (1970): Effect of alcohol on gastric emptying in man. Am. J. Clin. Nutr., 23, 1151-1153.

12) Buell, M. G., and Beck, I. T. (1983): Effect of ethanol on jejunal regional blood flow in the rabbit. Gastroenterology, 84, 81-89.

13) Chey, W. Y. (1972): Alcohol and gastric mucosa. Digestion, 7, 239-251.

14) Baraona, E. B., Pirola, R. C., and Lieber, C. S. (1974): Small intestine damage and changes in cell population produced by ethanol ingestion in the rat. Gastroenterology, 66, 226-234.

15) Schachter, D., and Rosen, S. M. (1959): Active transport of ${ }^{45} \mathrm{Ca}$ by the small intestine and its dependence on vitamin D. Am. J. Physiol., 196 (2), 357-362.

16) Schachter, D., Dowdle, E. B., and Schenker, H. (1960): Active transport of calcium by the small intestine in the rat. Am. J. Physiol., 198 (2), 263-268.

17) Younoszai, M. K., and Schedl, H. P. (1972): Intestinal calcium transport comparison of duodenum and ileum in vivo in the rat. Gastroenterology, 62, 565-571.

18) Petith, M. M., and Schedl, H. P. (1976): Duodenal and ileal adaptation to dietary calcium restriction: in vivo studies in the rat. Am. J. Physiol., 231, 865-871.

19) Zucoloto, S., and Rossi, M. A. (1976): Effect of alcohol ingestion on the epithelial cell population in rat small intestine. Experientia, 32, 614-616.

20) Rubin, E., Rybak, B. J., Lindenbaum, J., Gerson, C. D., Waller, G., and Lieber, C. S. (1972): Ultrastructural changes in the small intestine induced by ethanol. Gastroenterology, 63, 801-814.

21) Hoyumpa, A. M., Nichols, S. G., Wilson, F. A., and Schenker, S. (1977): Effect of ethanol on intestinal $(\mathrm{Na}, \mathrm{K}) \mathrm{ATPase}$ and intestinal thiamine transport in rats. $J$. $L a b$. Clin. Med., 90, 1086-1095.

22) Behar, J., and Kerstein, M. D. (1976): Intestinal calcium absorption: difference in transport between duodenum and ileum. Am. J. Physiol., 230, 1255-1260.

23) Oswald, N., and Binswager, U. (1979): Proximal and distal intestinal calcium transport in vitro as influenced by low calcium diet, uremia parathyroidectomy and 1,25dihydroxycholecalciferol treatment in rats. Res. Exp. Med., 175, 19-30.

24) Bronner, F., Bellaton, C., and Pansu, D. (1982): Saturable and nonsaturable Ca transport in rat intestine (Abstract). Fed. Proc., 41, 278.

25) Toraason, M. (1983): Calcium flux in vivo in the rat duodenum and ileum during pregnancy and lactation. Am. J. Physiol., 245, G624-G627.

26) Nellans, H. N., and Kimberg, D. V. (1978): Cellular and paracellular calcium transport in rat ileum: effects of dietary calcium. Am. J. Physiol., 235, E726-E737. 